\title{
THE MORPHOLOGICAL AND IMMUNOCYTOCHEMICAL EVALUATION OF PRIMARY RAT HEPATOCYTES UNDERGOING SPONTANEOUS CELL DEATH: MODULATION BY THE NITRIC OXIDE DONOR $S$-NITROSO- $N$ - ACETYLPENICILLAMINE
}

\author{
Tomas Kucera ${ }^{a *}$, Nikolina Kutinova Canova ${ }^{\mathrm{b}}$, Hassan Farghali ${ }^{\mathrm{b}}$, Jindrich Martinek ${ }^{\mathrm{a}}$ \\ ${ }^{a}$ Institute of Histology and Embryology, $1^{\text {st }}$ Faculty of Medicine, Charles University, Prague, Czech Republic \\ ${ }^{b}$ Institute of Pharmacology, ${ }^{\text {st }}$ Faculty of Medicine, Charles University, Prague \\ e-mail: tkucer@lfl.cuni.cz
}

Received: April 11, 2006; Accepted: May 15, 2006

Key words: Apoptosis/Nitric oxide/Primary rat hepatocytes/Caspase-3/S-nitroso-N-acetylpenicillamine/Immunocytochemistry

Nitric oxide (NO) is one of the smallest molecules synthesised in the human body. It is produced by three distinct nitric oxide synthase isoenzymes (NOS) and plays a number of physiological functions in many organs and tissues. Among its numerous properties is the ability to influence programmed cell death. NO can either inhibit or induce apoptosis depending on the context of its production. In the liver, NO is produced in greater amounts especially during inflammation. The effect of NO in liver physiology and pathophysiology can be both beneficial and detrimental. Therefore, the aim of our study was to examine NO effect on cell viability and cell death in primary rat hepatocyte culture. By using NO donor, S-nitroso-N-acetylpenicillamine (SNAP), the potential of exogenously delivered NO to influence spontaneous cell death in culture was examined. The morphological approach was used in order to discriminate between apoptotic and necrotic cell death. The nitrite level, urea production and alanine aminotransferase leakage were determined in the culture medium. The immunocytochemical detection of three apoptotic markers: cleaved caspase-3, cleaved caspase-9 and lamin A, was performed. Immunocytochemical analysis of hepatocyte apoptosis revealed different labelling pattern for each method, while the detection of cleaved caspase-3 best correlated with defined phenotypical criteria. Our data showed that under present conditions NO improved the viability of primary rat hepatocytes compared to untreated cells. This was manifested by the increase of viable hepatocytes in contrast to the decrease of necrotic and apoptotic hepatocytes as assessed by the morphological examination of cell culture. The NO effect was dose-dependent in the range of SNAP concentration between 200-800 $\mu \mathrm{M}$.

\section{INTRODUCTION}

Nitric oxide (NO) is endogenously produced and a highly reactive free radical that takes part in the regulation of many physiological and pathophysiological processes in practically every organ ${ }^{1}$. Its production is accomplished by three nitric oxide synthases existing in the human organism. There are two constitutive isoforms, endothelial (eNOS) and neuronal (nNOS), which are expressed mainly in endothelial and nerve cells $\mathrm{s}^{2,3}$. These constitutive isoforms intermittently produce smaller amounts of NO. The inducible isoform (iNOS) is expressed as a response to cytokines or as a result of stimulation by bacterial products and produces great amounts of NO. NO-induced effects are studied in various physiological and pathological circumstances by exploiting a number of models. Basically, there are two possible approaches to influence the processes which can be affected by NO. One approach is based on the modulation of NOSs activity. The other methods use various NO-releasing compounds (NO donors) to increase NO levels. Similar to the situation in other organ systems, NO production in the liver can have either beneficial or detrimental consequences ${ }^{4,5}$. The isoform of NOS that produces NO in a given situation is of particular significance for the outcome of $\mathrm{NO}$ action. Hepatic blood circulation, for example, is sustained by NO constitutively produced by $\mathrm{NOS}^{6}$. The stimulation of iNOS expression and the production of greater amounts of NO by this isoform can have positive effects in liver regeneration on the one hand ${ }^{7}$ or, on the other hand, it can contribute to oxidative liver injury and circulatory failure ${ }^{8}$. Another important aspect of NO interaction with cellular functions is its effect on apoptosis. There are studies, which indicate that NO possesses antiapoptotic effects in the liver as NO improves hepatocyte survival after liver injury caused by apoptosis inducing agents ${ }^{9}, 10$.

In the present study we evaluated the effect of the NO donor, S-nitroso-N-acetylpenicillamine (SNAP), on the viability and several other functional parameters of primary rat hepatocytes. In an attempt to distinguish between various modes of cell death we evaluated some methods of apoptosis detection in hepatocyte culture. Several immunocytochemically detected apoptotic markers were compared with the morphological evaluation of 
cell viability. The morphological criteria were also used for quantitation of apoptotic and necrotic cells.

\section{MATERIAL AND METHODS}

\section{Experimental animals}

For the present study, male rats of Wistar strain (Velaz-Lysolaje, 200-280 g of body weight) were used. The experimental procedures with rats were carried out in accordance with the general guidelines of the $1^{\text {st }}$ Faculty of Medicine, Charles University in Prague, for animal care and were approved by the Faculty Ethical Committee.

\section{Primary rat hepatocyte cultures}

Hepatocytes were isolated from rats by the two-step collagenase perfusion method as previously reported ${ }^{11}$. As assessed by trypan blue exclusion, cell viability after the isolation was more than $90 \%$. Cells were plated into $35-\mathrm{mm}$ collagen-coated cell culture dishes provided with sterile glass coverslips $22 \times 22 \mathrm{~mm}$ and maintained at $37{ }^{\circ} \mathrm{C}, 95 \%$ air and $5 \% \mathrm{CO}_{2}$ in William's medium E, supplemented with gentamicin, L-glutamine and $5 \%$ foetal bovine serum. After 3-h attachment period the medium was changed.

Experimental design: To evaluate SNAP-induced effects, two protocols were followed. In both protocols, SNAP was added to the medium after the attachment period to obtain desired concentration. In the first experiment, cells were incubated for different time intervals $(3,6,9,12 \mathrm{~h})$ in the medium without (control) or with $200 \mu \mathrm{mol} / 1$ SNAP. It was followed by another experiment where cells were treated with SNAP (0, 200, 400 and $800 \mu \mathrm{mol} / \mathrm{l}$ ) for $9 \mathrm{~h}$. After the incubation, medium was collected for biochemical analysis and cultures were processed for morphological examination.

\section{Biochemical analysis}

Urea concentration and alanine aminotransferase (ALT) leakage to the culture medium were determined using commercial kits (Sigma-Aldrich, Prague, Czech Republic). Nitrite levels in the cell culture supernatant were measured colorimetrically using Griess reagent ${ }^{12}$.

\section{Light microscopy and quantitative evaluation}

For light microscopic examination, treated and control cell cultures grown on coverslips were fixed with $4 \%$ formaldehyde and stained by haematoxylin-eosin (H-E) method. The following types of cultivated cells were quantified according to their morphology in H-E staining as viable cells, apoptotic cells and necrotic cells. Cells on each coverslip were counted in 20 randomly chosen nonoverlapping fields in $63 \mathrm{x}$ objective magnification.

\section{Electron microscopy}

Cells from control culture were fixed at $4{ }^{\circ} \mathrm{C}$ with Karnovsky's solution: $2 \%$ paraformaldehyde, $2.5 \%$ glutaraldehyde in $0.08 \mathrm{M} \mathrm{Na-cacodylate} \mathrm{buffer} \mathrm{(} \mathrm{pH} 7.4$ ), with the addition of $20 \mathrm{mg} \mathrm{CaCl}_{2} / 100 \mathrm{ml}$ of the fixative fluid. Thereafter, cells were harvested using a rubber scraper, centrifuged and osmicated. Cells were then mixed with liquid agarose, which formed gel after cooling. Pieces of agarose gel (approximately $1 \mathrm{~mm}^{3}$ ) containing hepatocytes were then dehydrated and processed into Epon.

\section{Immunocytochemistry}

The detection of immunocytochemical apoptotic markers was performed on untreated primary rat hepatocytes cultured for approximately $12 \mathrm{~h}$. After this time period, both apoptotic and necrotic cells were present in sufficient quantity. For the detection of cleaved caspase-3, cells were briefly washed with phosphate-buffered saline (PBS) and fixed with $4 \%$ paraformaldehyde in PBS ( $\mathrm{pH}$ 7.4) for $20 \mathrm{~min}$ at $4{ }^{\circ} \mathrm{C}$. Thereafter, coverslips with cells were washed with PBS and Tris-buffered saline $+0.1 \%$ Triton X-100 (TBS/T). Unspecific antibody binding was blocked by incubation with $5 \%$ normal goat serum (Sigma-Aldrich, Prague, Czech Republic) in TBS/T for $60 \mathrm{~min}$. After $5 \mathrm{~min}$ wash with TBS/T, anti-cleaved caspase-3 (Asp 175) rabbit polyclonal antibody (\#9661; Cell Signaling Technology, Beverly, MA, USA) diluted 1:800 in TBS/T $+5 \%$ normal goat serum was applied for $60 \mathrm{~min}$ at room temperature. To block endogenous peroxidase activity coverslips were immersed in $0.6 \%$ hydrogen peroxide in TBS. After $30 \mathrm{~min}$, coverslips were washed with TBS/T and incubated with secondary antibody DAKO EnVision+, peroxidase, Rabbit (DAKO, Carpinteria, CA, USA) for $30 \mathrm{~min}$ at room temperature. Visualization was performed using diaminobenzidine (DAB; DAKO) substrate-chromogen solution. Coverslips were washed in $\mathrm{H}_{2} \mathrm{O}$ and mounted with DAKO Faramount aqueous mounting medium. Some coverslips were counterstained with Harris's haematoxylin.

For the detection of cleaved Lamin A, cells were briefly washed with PBS and fixed with $4 \%$ paraformaldehyde in PBS ( $\mathrm{pH} \mathrm{7.4)} \mathrm{for} 10 \mathrm{~min}$ at $4{ }^{\circ} \mathrm{C}$. Permeabilization was done using $0.2 \%$ Triton X-100 in PBS for 5 min at room temperature. After washes in TBS/T coverslips were blocked with $5 \%$ normal goat serum in TBS/T for $60 \mathrm{~min}$. Cells were washed with TBS and then incubated with anticleaved lamin A (Asp230) rabbit polyclonal antibody (\#2031; Cell Signaling Technology) diluted $1: 100$ in TBS for $12 \mathrm{~h}$ at $4{ }^{\circ} \mathrm{C}$. The blockage of endogenous peroxidase activity and visualization was performed as described in cleaved caspase- 3 detection protocol.

For the detection of cleaved caspase-9, cells were briefly washed with PBS and fixed with $4 \%$ paraformaldehyde in PBS (pH 7.4) for 10 min at $4{ }^{\circ} \mathrm{C}$. After washes in TBS/T coverslips were blocked with $5 \%$ normal goat serum in TBS/T for $60 \mathrm{~min}$. Coverslips were then incubated with anti-cleaved caspase-9 (Asp353) antibody (rat specific) rabbit polyclonal antibody (\#9507; Cell Signaling Technology) diluted $1: 400$ in TBS for $12 \mathrm{~h}$ at $4{ }^{\circ} \mathrm{C}$. The blockage of endogenous peroxidase activity and visualization was performed as described above.

\section{Statistical evaluation}

Data obtained from the quantitative morphological evaluation of cultures incubated with different concentrations of SNAP were analysed by a two-way analysis 
of variance (ANOVA). An alpha-value equal or less than 0.05 was considered statistically significant.

\section{RESULTS}

\section{Morphological evaluation of the effect of snap on primary} rat hepatocyte viability

For the quantitation of hepatocyte viability we have evaluated the cell morphology in haematoxylin-eosin staining where the following criteria were applied. Those cells, which attached to the layer of collagen and became rather flat in comparison to liver cells in vivo, were classified as viable. The adhesion of hepatocytes to the substratum could be observable already several hours after seeding. These cells had one or two round nuclei with evenly dispersed fine chromatin in which nucleoli could be distinguished (Fig. 1A). Those cells that were rounded and apparently began to detach from the substratum were regarded as necrotic. Moreover, these cells had darkly staining nuclei and pale, grey-coloured, granular cytoplasm (Fig. 1B). Apoptotic cells had characteristic blebs, homogenously eosinophilic cytoplasm and compacted nuclear chromatin or fragmented nuclei (Fig. 1C). These criteria
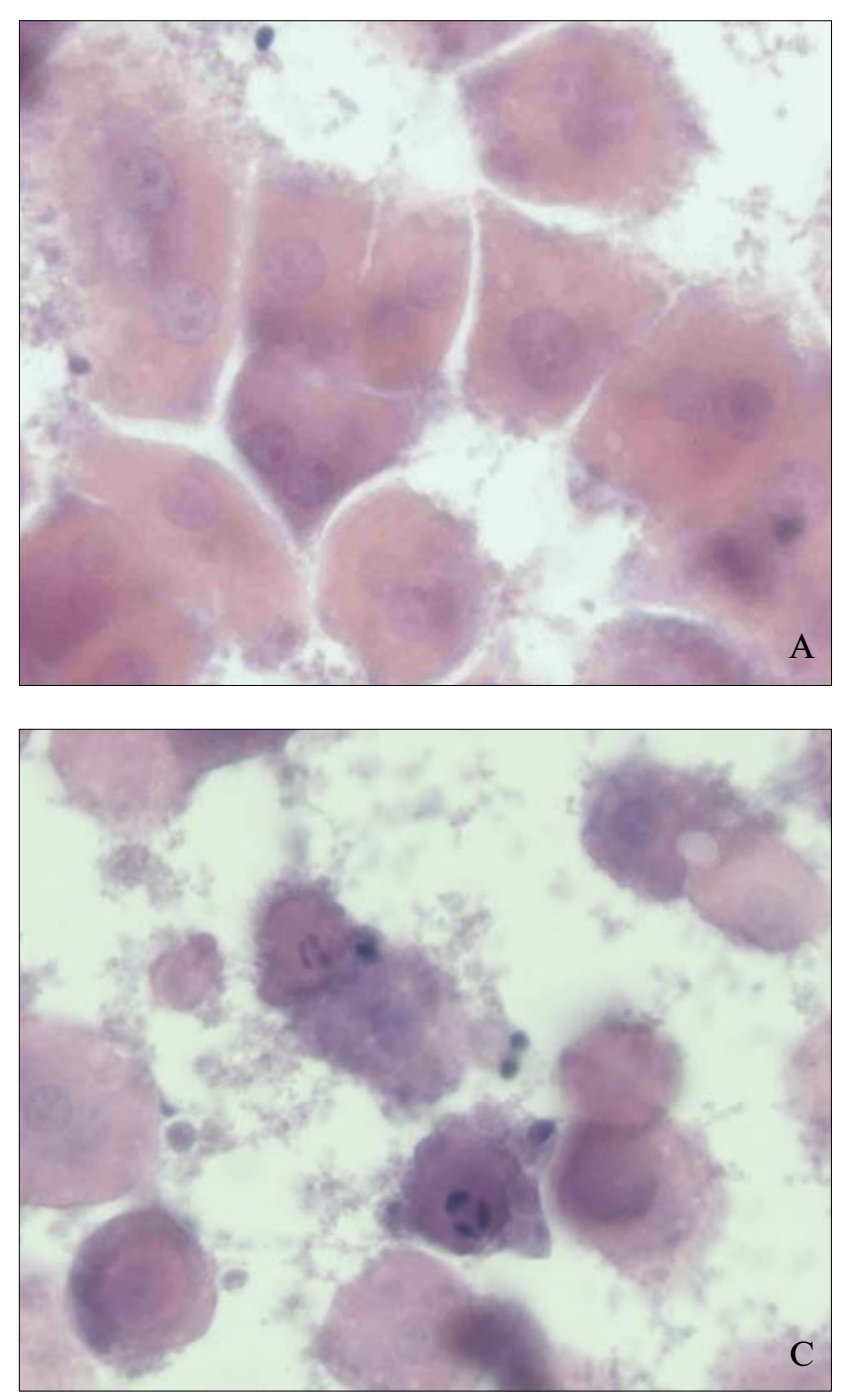

were previously verified by the ultrastructural examination of cultured hepatocytes. Using electron microscopy, we could observe that viable and adherent hepatocytes had preserved cellular ultrastructure (Fig. 2). Apoptotic hepatocytes had intact cytoplasmic membranes. Their organelles, though densely packed due to the shrinkage of cells, were without significant alterations (Fig. 3). Meanwhile, cells presumed to be necrotic had disrupted cell membranes as well as disintegrated mitochondria and other membranous cellular components (Fig. 4). These characteristics pointed to an uncontrolled mode of cell death - necrosis.

The viability of hepatocytes in culture gradually decreased in time (Tab. 1). At the early phase of cultivation (3h after attachment) cell death was mainly necrotic. After $6 \mathrm{hrs}$ of cultivation, first apoptotic hepatocytes appeared. The percentage of both necrotic and apoptotic cells then further increased. The effect of added NO on the time course of these degenerative changes was analysed in the experiment where cells were incubated with $200 \mu \mathrm{M}$ of SNAP. After quantitative evaluation of cultures in different time periods, it was found that the number of viable cells in SNAP-treated cultures was higher in all time intervals (after 3, 6, 9 and $12 \mathrm{~h}$ of cultivation) compared

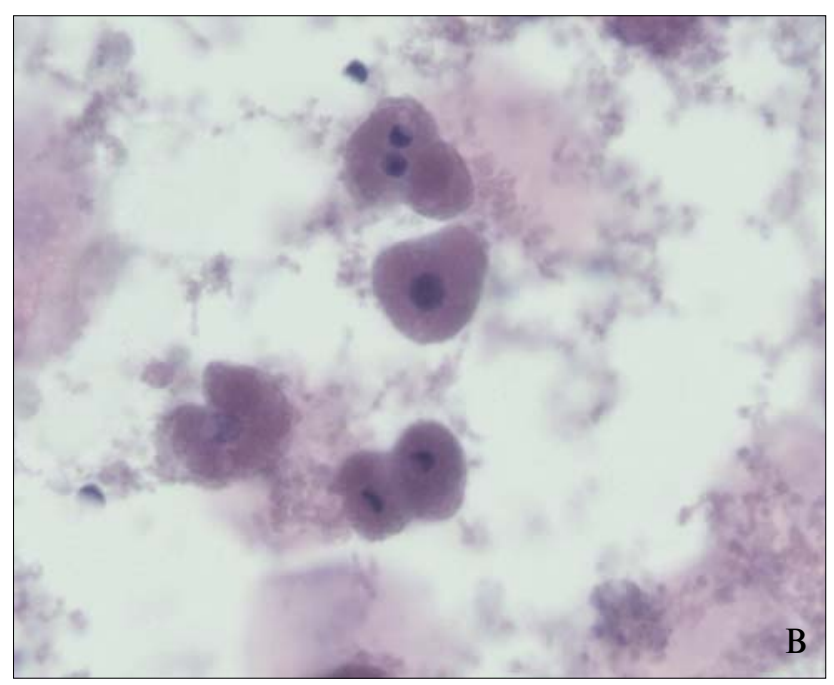

Fig. 1. (A) Viable and adherent primary rat hepatocytes. Nuclei contain finely dispersed chromatin. (B) Necrotic hepatocytes detached from the substratum display pale staining granular cytoplasm and dark (pyknotic) nuclei. (C) Two apoptotic hepatocytes. Note cytoplasmic protrusions (blebs) and nuclei with the condensed chromatin located on the nuclear periphery. (Haematoxylin-eosin staining, Obj. mag. 63X). 
Table 1. Quantitative evaluation of hepatocyte viability. Cells were incubated with SNAP (0, 200 $\mu \mathrm{M})$ and counted according to their morphology at 3,6,9 and $12 \mathrm{~h}$.

\begin{tabular}{|c|c|c|c|c|c|}
\hline \multicolumn{3}{|c|}{ SNAP concentration incubation time } & \multicolumn{3}{|c|}{ cell type } \\
\hline & & & viable & apoptot & necrotic \\
\hline \multicolumn{6}{|l|}{0 mikromol/l } \\
\hline & \multirow[t]{2}{*}{$3 \mathrm{~h}$} & average & 80,9 & 0,3 & 18,8 \\
\hline & & SEM & 2,7 & 0,0 & 2,7 \\
\hline & \multirow[t]{2}{*}{$6 \mathrm{~h}$} & average & 78,9 & 2,1 & 19,0 \\
\hline & & SEM & 2,2 & 0,3 & 2,4 \\
\hline & \multirow[t]{2}{*}{$9 \mathrm{~h}$} & average & 65,1 & 10,2 & 24,6 \\
\hline & & SEM & 2,4 & 0,8 & 3,2 \\
\hline & \multirow[t]{2}{*}{$12 \mathrm{~h}$} & average & 53,9 & 20,5 & 25,6 \\
\hline & & SEM & 2,1 & 1,3 & 3,3 \\
\hline \multicolumn{6}{|l|}{200 mikromol/l } \\
\hline & \multirow[t]{2}{*}{$3 \mathrm{~h}$} & average & 87,3 & 0,6 & 12,1 \\
\hline & & SEM & 0,5 & 0,1 & 0,5 \\
\hline & \multirow[t]{2}{*}{$6 \mathrm{~h}$} & average & 85,6 & 0,8 & 13,6 \\
\hline & & SEM & 0,8 & 0,1 & 0,7 \\
\hline & \multirow[t]{2}{*}{$9 \mathrm{~h}$} & average & 81,1 & 6,0 & 12,9 \\
\hline & & SEM & 1,3 & 0,8 & 0,9 \\
\hline & \multirow[t]{2}{*}{$12 \mathrm{~h}$} & average & 67,6 & 15,4 & 17,0 \\
\hline & & SEM & 3,8 & 0,6 & 4,2 \\
\hline
\end{tabular}

Table 2. Quantitative evaluation of hepatocyte viability at 9h of incubation with SNAP (0, 200, 400, $800 \mu \mathrm{M})$. Cells were counted according to their morphology as viable, necrotic or apoptotic. ${ }^{*}$ Statistically significant as compared with control culture.

\begin{tabular}{|c|c|c|c|c|}
\hline \multirow{2}{*}{\multicolumn{2}{|c|}{$\begin{array}{c}\text { SNAP concentration } \\
\text { mikromol/l }\end{array}$}} & \multicolumn{3}{|c|}{ percentage of examined cells } \\
\hline & & viable & apoptotic & necrotic \\
\hline \multirow[t]{2}{*}{0} & average & 69,8 & 7,5 & 22,6 \\
\hline & SEM & 1,7 & 0,5 & 2,2 \\
\hline \multirow[t]{2}{*}{200} & average & $74,7^{\star}$ & 8,5 & 16,8 \\
\hline & SEM & 1,1 & 0,1 & 1,0 \\
\hline \multirow[t]{2}{*}{400} & average & $78,1^{*}$ & $5,7^{\star}$ & $16,2^{\star}$ \\
\hline & SEM & 0,9 & 0,6 & 1,5 \\
\hline \multirow[t]{2}{*}{800} & average & $83,7^{*}$ & $1,8^{*}$ & $14,5^{\star}$ \\
\hline & SEM & 0,7 & 0,3 & 0,8 \\
\hline
\end{tabular}

Table 3. Biochemical analysis of culture medium after $9 \mathrm{~h}$ of cultivation with increasing concentrations of SNAP.

\begin{tabular}{|llcccc|}
\hline incubation time & 9 hours & control & SNAP 200 $\boldsymbol{\mu M}$ & SNAP 400 $\boldsymbol{\mu M}$ & SNAP 800 $\boldsymbol{\mu M}$ \\
\hline nitrite levels (mM) & & 21,08 & 52,43 & 84,12 & 167,33 \\
& & 25,04 & 49,52 & 85,55 & 171,16 \\
& & 20,68 & 52,17 & 94,63 & 171,22 \\
\cline { 2 - 6 } & average & $\mathbf{2 2 , 2 6}$ & $\mathbf{5 1 , 3 7}$ & $\mathbf{8 8 , 1 0}$ & $\mathbf{1 6 9 , 9 0}$ \\
& SEM & 1,14 & 0,76 & 2,69 & 1,05 \\
\hline urea concentration (mg/dcl) & & 10,00 & 11,12 & 19,28 & 10,80 \\
& & 12,56 & 11,60 & 11,04 & 13,12 \\
& & 11,52 & 11,12 & 10,32 & 15,36 \\
\cline { 2 - 6 } & average & $\mathbf{1 1 , 3 6}$ & $\mathbf{1 1 , 2 8}$ & $\mathbf{1 3 , 5 5}$ & $\mathbf{1 3 , 0 9}$ \\
& SEM & 0,61 & 0,13 & 2,35 & 1,07 \\
\hline ALT concentration (U/L) & & 31,03 & 37,37 & 50,24 & 32,92 \\
& & 39,25 & 50,19 & 39,14 & 32,71 \\
& & 31,50 & 32,34 & 50,03 & 49,09 \\
\cline { 2 - 5 } & average & $\mathbf{3 3 , 9 3}$ & $\mathbf{3 9 , 9 7}$ & $\mathbf{4 6 , 4 7}$ & $\mathbf{3 8 , 2 4}$ \\
& SEM & 2,18 & 4,34 & 2,99 & 4,43 \\
\hline
\end{tabular}


to control. The greatest effect of SNAP on the viability of hepatocytes, as seen in Tab. 1, was observed after $9 \mathrm{~h}$ of cultivation.

This $9 \mathrm{~h}$ incubation period was then chosen for experiment to examine the effect of different SNAP concentrations. As Tab. 2 shows, the number of viable hepatocytes increased and the number of necrotic and apoptotic hepatocytes decreased dose dependently when cells were treated with SNAP $(200,400,800 \mu \mathrm{M})$.

\section{Nitrite levels in the medium after snap addition} and biochemical evaluation of no effects

By determining the NO-end oxidation product, nitrite, in the culture medium, it was confirmed that NO was in

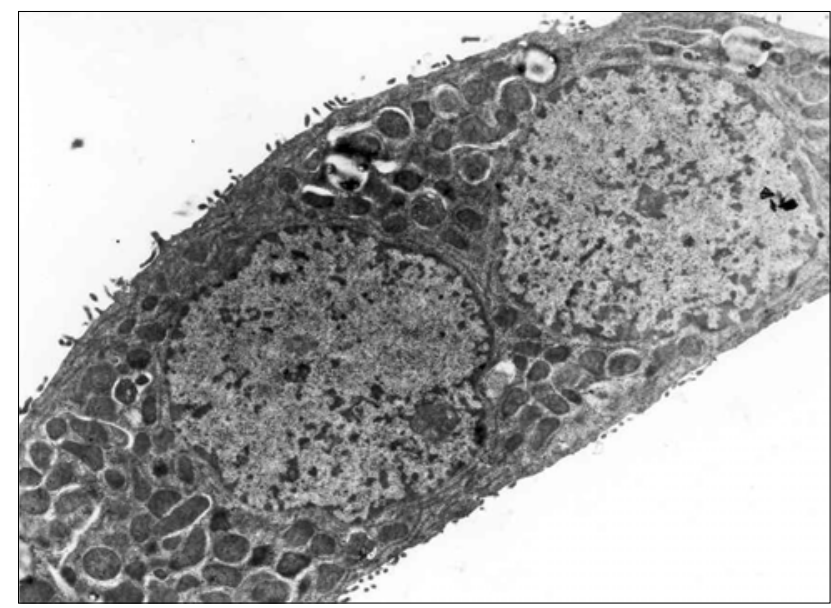

Fig. 2. Electron micrograph of a binucleate hepatocyte with the flattened basal surface reflecting its adhesion to the substratum. Ultrastructure corresponds to the viable phenotype of the primary hepatocyte in culture. (Orig. mag. 12500X).

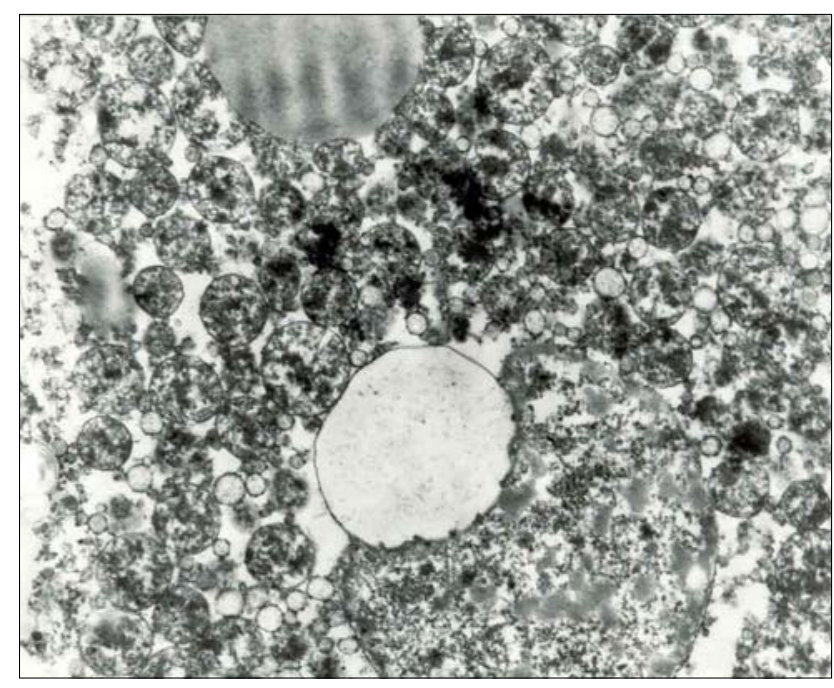

Fig. 4. Electron micrograph of a necrotic hepatocyte. Membranous structures lost their integrity as a result of uncontrolled cell lysis. (Orig. mag. 15000X). fact released from SNAP. Nitrite levels increased gradually as a function of time. In the experiment where different amounts of SNAP were used, nitrite levels increased in a dose dependent manner. ALT leakage to the culture medium as well as urea production was not affected by SNAP (see Tab. 3).

\section{Immunocytochemical evaluation of hepatocyte spontaneous apoptosis}

In order to further validate our morphological criteria for apoptosis detection we tried to detect some apoptotic markers using the immunocytochemical approach. The immunocytochemical detection of three apoptotic markers: activated caspase-3, activated caspase- 9 and cas-

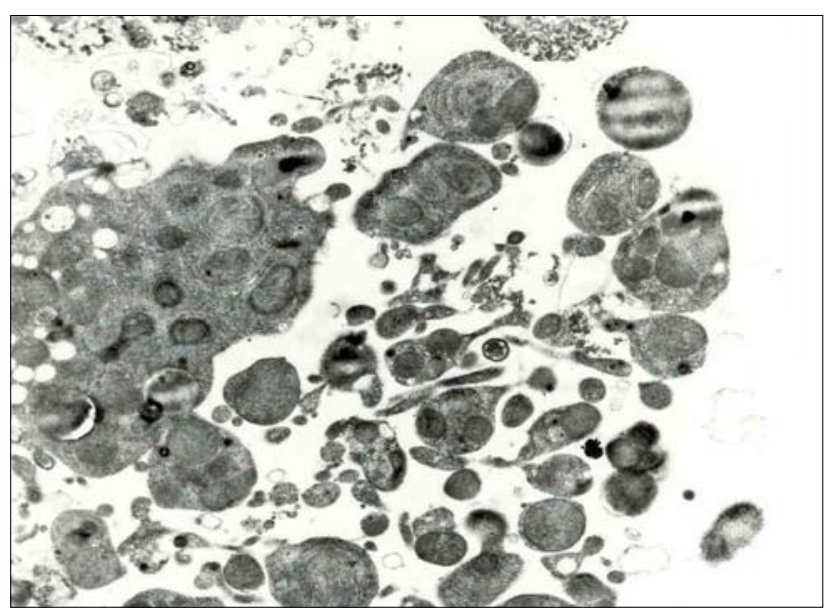

Fig. 3. Electron micrograph of an apoptotic hepatocyte after it fragmented into apoptotic bodies containing relatively preserved organelles surrounded by intact membranes. (Orig. mag. 12000X).

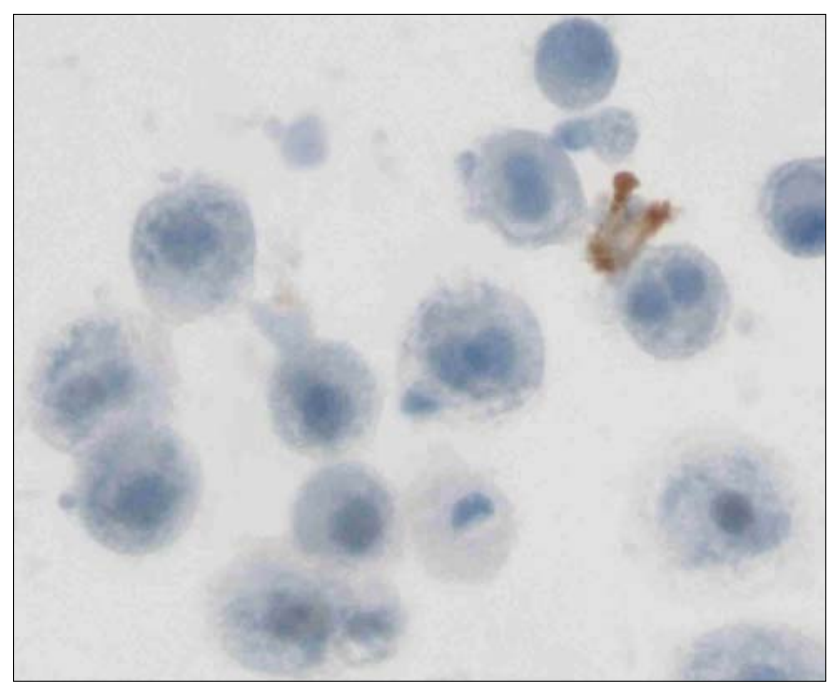

Fig. 5. Immunocytochemical detection of active caspase3. Positively labelled cell with typical apoptotic morphology. (Immunoperoxidase reaction -DAB, haematoxylin counterstaining, Obj. mag. 63X). 


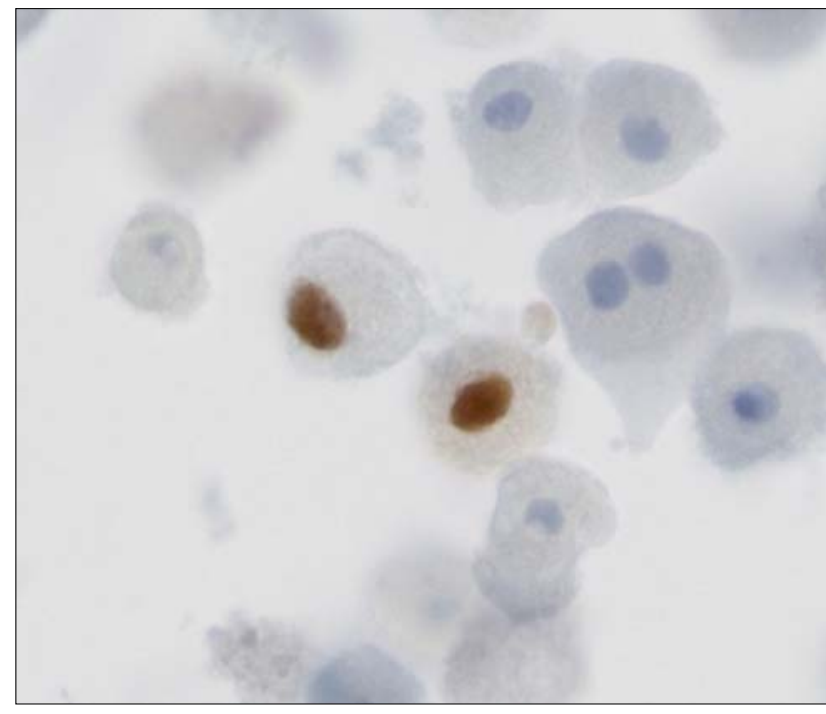

Fig. 6. Immunocytochemical detection of cleaved lamin A. The immunoreactivity is localized in the nuclei of some rounded and detached necrotic cells, meanwhile the majority of these cells, as can be noted on this photograph, is negative. (Immunoperoxidase reaction -DAB, haematoxylin counterstaining, Obj. mag. 63X).

pase-cleaved lamin A, was performed. Cells labelled with the antibody against cleaved caspase- 3 were the same as those classified as apoptotic in haematoxylin-eosin staining (Fig. 5).

The results of the immunocytochemical detection of cleaved lamin A showed that the cell labelling was somewhat different from that obtained using cleaved caspase3 antibody. Cleaved lamin A immunopositivity could be located in nuclei or nuclear fragments of apoptotic cells as well as in some cells considered to be necrotic (Fig. 6). Similar results were obtained after the detection of active caspase-9 (Fig. 7). In this case, the immunoreaction was positive not only in the cytoplasm of the blebbing apoptotic hepatocytes and apoptotic bodies, but also in some cells with necrotic features.

\section{DISCUSSION}

We examined the potential of NO donor SNAP to suppress spontaneous apoptosis of primary rat hepatocytes. SNAP improved rat hepatocyte viability as manifested by an increase in viable compared to dead cells in treated cultures. NO apparently decreased both types of cell death. However, NO did not abolish spontaneous cell death in culture completely. It should be taken into the account that, to a certain extent, the isolation and processing of cells for cultivation is a kind of stress in itself. Therefore, although the initial viability of isolated hepatocytes was more than $90 \%$, after 3 hours of cultivation there was apparent decrease in the number of viable cells. This spontaneous loss of viability is caused by the obvious difference

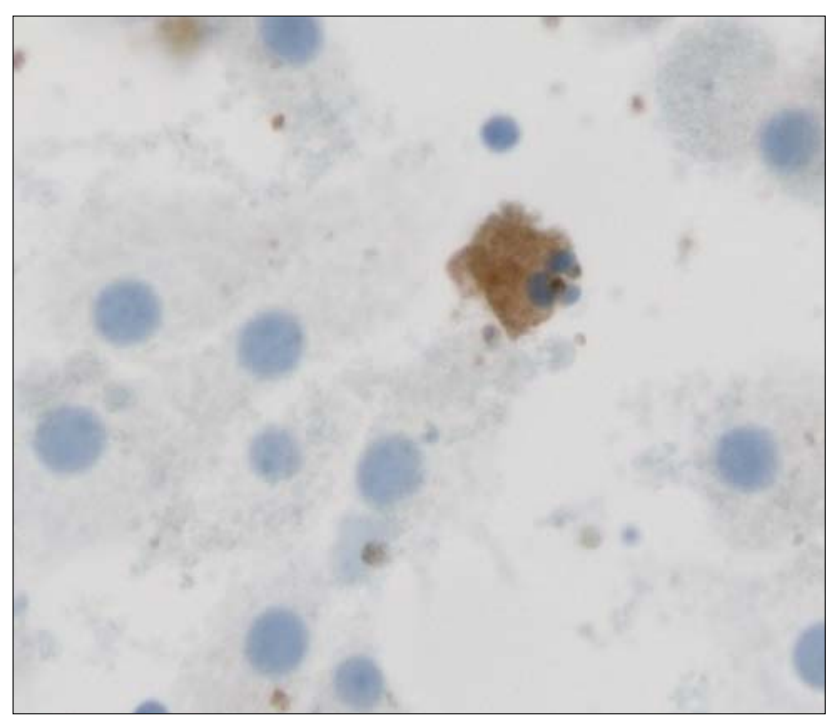

Fig. 7. Immunocytochemical detection of active caspase9 shows positivity in the cytoplasm of an apoptotic hepatocyte containing nuclear fragments. Neighbouring adherent cells display no immunoreactivity. (Immunoperoxidase reaction -DAB, haematoxylin counterstaining, Obj. mag. 63X).

in hepatocyte environment between in vivo and in vitro situation. The type of attachment substratum, cell density and the composition of culture media (especially the addition of some hormones) can significantly influence but not completely abrogate the rate of apoptosis in primary hepatocyte culture ${ }^{13}$. The importance of cell attachment for maintaining the epithelial cell viability is emphasised, for example, by the finding that already $15 \mathrm{~min}$ after cells had detached from the substratum proapoptotic molecule Bax was activated ${ }^{14}$.

Within the present experimental conditions it was demonstrated that NO was beneficial, which is in agreement with the previous findings of NO antiapoptotic effects in hepatocyte cultures ${ }^{15,16}$, but not relevant to the report on apoptosis caused by NO (ref. ${ }^{17}$ ).

Here, exogenously delivered NO did not alter urea production - a functional parameter of cultured hepatocytes. This probably reflects NO ability to improve hepatocyte viability by preventing cell death rather then by stimulating hepatocyte metabolic activity. Moreover, the common substrate for NO and urea synthesis is L-arginine. NO can inhibit activity of arginase, which converts L-arginine to L-citruline in urea cycle, thus exogenously delivered NO can inhibit urea synthesis ${ }^{18}$. Furthermore, as assessed by ALT leakage from the cells to the culture media, SNAP did not affect cell membrane integrity when compared to basal conditions, which supports our morphological findings of the stabilising effect of exogenous NO against spontaneous cell death.

As a part of the present study of primary rat hepatocyte apoptosis and necrosis we evaluated various apoptotic markers that could be used to distinguish between 
different modes of cell death. In our previous study of cyclosporine A effects on primary rat hepatocytes we applied Annexin V-biotin to label apoptotic cells in culture. However, our results did not allow us to discriminate between apoptotic and necrotic hepatocytes since Annexin V labelled cells undergoing both types of cell death ${ }^{19}$.

Data presented in this study show that comparison of immunocytochemical detection of apoptotic markers with the morphological assessment of hepatocyte morphology makes it possible to determine the specificity of applied methods. The best correlation between morphological criteria and immunocytochemistry was found by using antibody against active caspase-3. When antibodies against cleaved lamin A or active caspase-9 were applied, they also labelled cells that were apparently necrotic or were perhaps in a late stage of apoptosis, so called secondary necrosis. The antibody against cleaved lamin A recognizes the epitop that appears after specific cleavage of lamin A by active caspase- 6 . The immunoreactivity for cleaved lamin A implies, that caspase- 6 was active in these cells considering that this caspase is the only one known to act on lamin $\mathrm{A}$ in the execution phase of apoptosis ${ }^{20}$. Furthermore, caspase- 6 is activated after cleavage by caspase-3 (ref. ${ }^{21}$ ). Since not all necrotic hepatocytes were positive for cleaved lamin A and the majority of apoptotic cells were labelled, we conclude that this epitop is retained in the apoptotic cells even after they proceed to secondary necrosis. This conclusion is also confirmed for the result of cleaved caspase- 9 detection. The question whether this caspase is still active in the final phase of apoptosis remains unresolved. In contrast to cleaved lamin $A$ and active caspase- 9 immunoreactivity, the positive labelling of hepatocytes for active caspase- 3 disappears in these late apoptotic or rather secondary necrotic cells. These findings allow immunocytochemical differentiation between various steps of the apoptotic process.

\section{CONCLUSION}

Our data support a modulatory effect of the NO donor SNAP on primary rat hepatocytes. This modulatory effect was documented by the increased number of viable cells and decreased number of apoptotic and necrotic cells in treated cultures. The criteria for the morphological evaluation of hepatocyte viability and hepatocyte cell death were confirmed using apoptotic markers: cleaved caspase-3, cleaved caspase- 9 and lamin A, which allow one to detect apoptotic cells in various stages of cell death. Be applying these markers it will be possible to delineate the effect of NO on primary rat hepatocyte viability in this culture system in future studies dealing with different kinds of cell injury.

\section{ACKNOWLEDGEMENTS}

This work was supported by the Research Project MSM 0021620807 of the Ministry of Education, Youth and Sports of the Czech Republic.

\section{REFERENCES}

1 Billiar TR. (1995) Nitric oxide: Novel biology with clinical relevance. Ann Surg 221, 339-349.

2 Ignarro LJ, Buga GM, Wood KS, Byrns RE, Chaudhuri G. (1987) Endothelium-derived relaxing factor produced and released from artery and vein is nitric oxide. Proc Natl Acad Sci USA 84, 92659269.

3 Bredt DS, Snyder SH. (1992) Nitric oxide, a novel neuronal messenger. Neuron 8, 3-11.

4 Li J, Billiar TR. (1999) Nitric Oxide IV. Determinants of nitric oxide protection and toxicity in liver. Am J Physiol 276, G10691073.

5 Farghali H, Canová N, Kučera T, Martínek J, Mašek K. (2003) Nitric oxide synthase inhibitors modulate lipopolysaccharide-induced hepatocyte injury: dissociation between in vivo and vitro effects. Int Immunopharmacol 3, 1627-1638.

6 Wiest R, Groszmann RJ. (2002) The paradox of nitric oxide in cirrhosis and portal hypertension: too much, not enough. Hepatology 35: 478-491.

7 Rai RM, Lee FYJ, Rosen A, Yang SQ, Lin HZ, Koteish A, Liew FY, Zaragoza C, Lowenstein C, Diehl AM. (1998) Impaired liver regeneration in inducible nitric oxide synthase- deficient mice. Proc Natl Acad Sci USA 95, 13829-13834.

8 Thiemermann C, Ruetten H, Wu CC, Vane JR. (1995) The multiple organ dysfunction syndrome caused by endotoxin in the rat: attenuation of liver dysfunction by inhibitors of nitric oxide synthase. $\mathrm{Br}$ J Pharmacol 116: 2845-2851.

9 Saavedra JE, Billiar TR, Williams DL, Kim YM, Watkins SC, Keefer LK. (1997) Targeting nitric oxide (NO) delivery in vivo. Design of a liver-selective NO donor prodrug that blocks tumor necrosis factor-alpha-induced apoptosis and toxicity in the liver. $\mathbf{J}$ Med Chem 40: 1947-54.

10 Liu J, Saavedra JE, Lu T, Song JG, Clark J, Waalkes MP, Keefer LK. (2002) O2-Vinyl 1-(pyrrolidin-1-yl) diazen-1-ium-1, 2-diolate protection against D-galactosamine/endotoxin-induced hepatotoxicity in mice: Genomic analysis using microarrays. J Pharmacol Exp Ther 300, 18-25.

11 Farghali H, Buchar E, Machková Z, Kameníková L, Mašek K. (1986) Muramyl dipeptide and carbon tetrachloride hepatotoxicity in rats: involvement of plasma membrane and calcium homeostasis in protective effect. Methods Find Exp Pharmacol 8, 469-477.

12 Pastor CM, Morris SM, Billiar TR. (1995) Sources of arginine for induced nitric oxide synthesis in the isolated perfused liver. Am J Physiol Gastrointest Liver Physiol 32, G861-866.

13 Qiao L, Farrell GC. (1999) The effects of cell density, attachment substratum and dexamethasone on spontaneous apoptosis of rat hepatocytes in primary culture. In Vitro Cell Dev-An 35, 417-424.

14 Wang P, Valentijn AJ, Gilmore AP, Streuli CH. (2003) Early events in the anoikis program occur in the absence of caspase activation. J Biol Chem 278: 19917-19925.

15 Li J, Bombeck CA, Yang S, Kim YM, Billiar TR. (1999) Nitric oxide suppresses apoptosis via interrupting caspase activation and mitochondrial dysfunction in cultured hepatocytes. J Biol Chem 274, 17325-17333.

16 Gumpricht E, Dahl R, Yerushalmi B, Devereaux MW, Sokol RJ (2002) Nitric oxide ameliorates hydrophobic bile acid-induced apoptosis in isolated rat hepatocytes by non-mitochondrial pathways. J Biol Chem 277, 25823-25830.

17 Wang JH, Redmond HP, Wu QD, Bouchier-Hayes D. (1998) 
Nitric oxide mediates hepatocyte injury. Am J Physiol 275: G1117G1126.

18 Morris SM. (2002) Regulation of enzymes of the urea cycle and arginine metabolism. Annual Review of Nutrition 22, 87-105.

19 Kučera T, Canová N. (2002) Cytotoxic effect of cyclosporin A on rat hepatocyte primary culture. Abstracts of the Annual Symposium of the Czech Society of Histochemistry and Cytochemistry. The Histochemical Journal 34, 457.
20 Orth K, Chinnaiyan AM, Garg M, Froelich CJ, Dixit VM. (1996) The CED-3/ICE-like protease Mch2 is activated during apoptosis and cleaves the death substrate lamin A. J Biol Chem 271, 1644316446.

21 Slee EA, Colin A, Martin SJ. (2001) Executioner caspase-3, -6, and -7 perform distinct, non-redundant roles during the demolition phase of apoptosis. J Biol Chem 276: 7320-7326. 